\title{
INTUSSUSCEPTION IN A CHILD WITH SPORADIC BURKITT LYMPHOMA
}

\author{
Angotti R, Ferrara F, Burgio A, Garzi A, Di Maggio G, Meucci D, Messina M
}

\author{
Division of Pediatric Surgery, Department of Pediatrics, Obstetrics and Reproductive Medicine \\ University Of Siena
}

Introduction. Burkitt Lymphoma is a high grade lymphoma and it represents 8-10\% of all tumors in children less than 15 years old. There are two forms of Burkitt Lymphoma (BL): endemic and sporadic, that are indistinguishable by histology, but they have got a different geographical distribution. The sporadic form more commonly has an abdominal presentation. About eighty percent of these patients has predominantly intussusceptions. Materials and methods. We report a 5 years old girl with spasmodic abdominal pain who was addimitted in our Clinic. We diagnosed an intussusception by clinical examination and abdominal ultrasound scan. We decided to perform an emergency operation and we found a single pedicle neoformation on the anti-mesenteric wall of ileum, that was the patologic lead point. We reduced the intussusception and we resected the neoformation and a small length of ileum (about $4 \mathrm{~cm}$ ). We performed a single-layer end-to-end ileo-ileum anastomosis and the appendicectomy. The histopathological examination and the immunohistochemistry study revealed a Burkitt Lymphoma. Results. The patient was dismissed on eighth postoperative day and she was referred to Pediatric Oncology Center for chemotherapy. The child was graded second class (R2) because lymph-nodes sampling was not performed and LDH levels were lower $500 \mathrm{U} / \mathrm{l}$. Conclusions. The mayority of sporadic Burkitt Lymphoma patients presents with abdominal disease that required a laparotomy. The presenting symptoms included: an abdominal mass, intestinal obstruction, intussusceptions as acute abdomen. The role of surgery is very controversial. However, it's required to confirm the diagnosis in the presence of extensive intrabdominal disease and to relieve the common presenting symptoms in the presence of acute abdomen. Some Authors argue that Surgery is important in the management of the complications.

Key words: intussusceptions, Sporadic Burkitt Lymphoma, ileum neoformation

\section{INTRODUCTION}

Burkitt Lymphoma is a high grade mature B-cell neoplasm and it represents 8-10\% of all tumors in children of age less than 15 years. It's composed of monomorphic medium-size B cells with basophilic cytoplasm and numerous mitotic figures $(1,2,3)$. We report the case of a 5 years-old girl with intussusception in Sporadic Burkitt Lymphoma. This report focus on the importance of considering the possibility of Burkitt lymphoma in ileum polyp and intussusception.

\section{CASe Report}

A 5 years old girl, with spasmodic abdominal pain, was addimitted in our Clinic. The episodes of pain were occurred with remarkable regularity for about one week and initially the child was behaved normally between the spasm. The physical examination showed a picture of acute abdomen whit diffuse pain and antalgic position. The anamnesis showed one episode of vomiting, regular alvus and absences of rectal bleeding. Because the symptoms suggested an intussusception an abdominal ultrasound scan was performed. The echography confirmed the diagnosis of intussusception and it showed an invagination of proximal bowel (intussusceptum) into the lumen of distal bowel (intus- suscipiens) (Fig.1). We decided to perform an emergency operation under general anesthesia. We made a right transvers skin incision above the umbilicus and we found an ileo-cecal-colic intussusception. Reduction of ileum through the ileocecal valve requires patience and it was achieved by squeezing the bowel distal to the apex of intussusceptum (Fig.2) . After reduction we discovered a pathological lead point on the anti-mesenteric wall of ileum, which was a peduncled polyp. Dimensions of the neoformation were $1 \mathrm{~cm} \times 2$ $\mathrm{cm}$. We resected the neoformation and a small length of ileum (about $4 \mathrm{~cm}$ ) (Fig.3). A single layer end-toend ileo ileum anastomosis was performed and the appendicectomy. The light microscopic appearance of the tumor suggested Burkitt Lymphoma. A complete and specific work-up was performed to choose the management of case. It included computer tomography of the chest (CT scan), chest x-ray, skeletal scintigraphy, abdominal, neck and head ultrasound scan, bone marrow aspirate, magnetic resonance imaging total body (MRI) and peripheal blood tests. Pretreatment LDH levels were measured routinely. All exams showed an absence of disease. However the child was graded second risk group (R2) because lymph-nodes sampling was not performed and LDH levels were lower $500 \mathrm{U} / \mathrm{l}$.

Correspondence to:

Prof. Mario Messina, Division of Pediatric Surgery, Dept of Pediatrics, Obstetrics and Reproductive Medicine.

University of Siena. Policlinico "Le Scotte" - Viale Bracci - 53100 - Siena - Italy

Telefono: +39577586501 - Fax: +39577586174

E-mail: messinam@unisi.it 

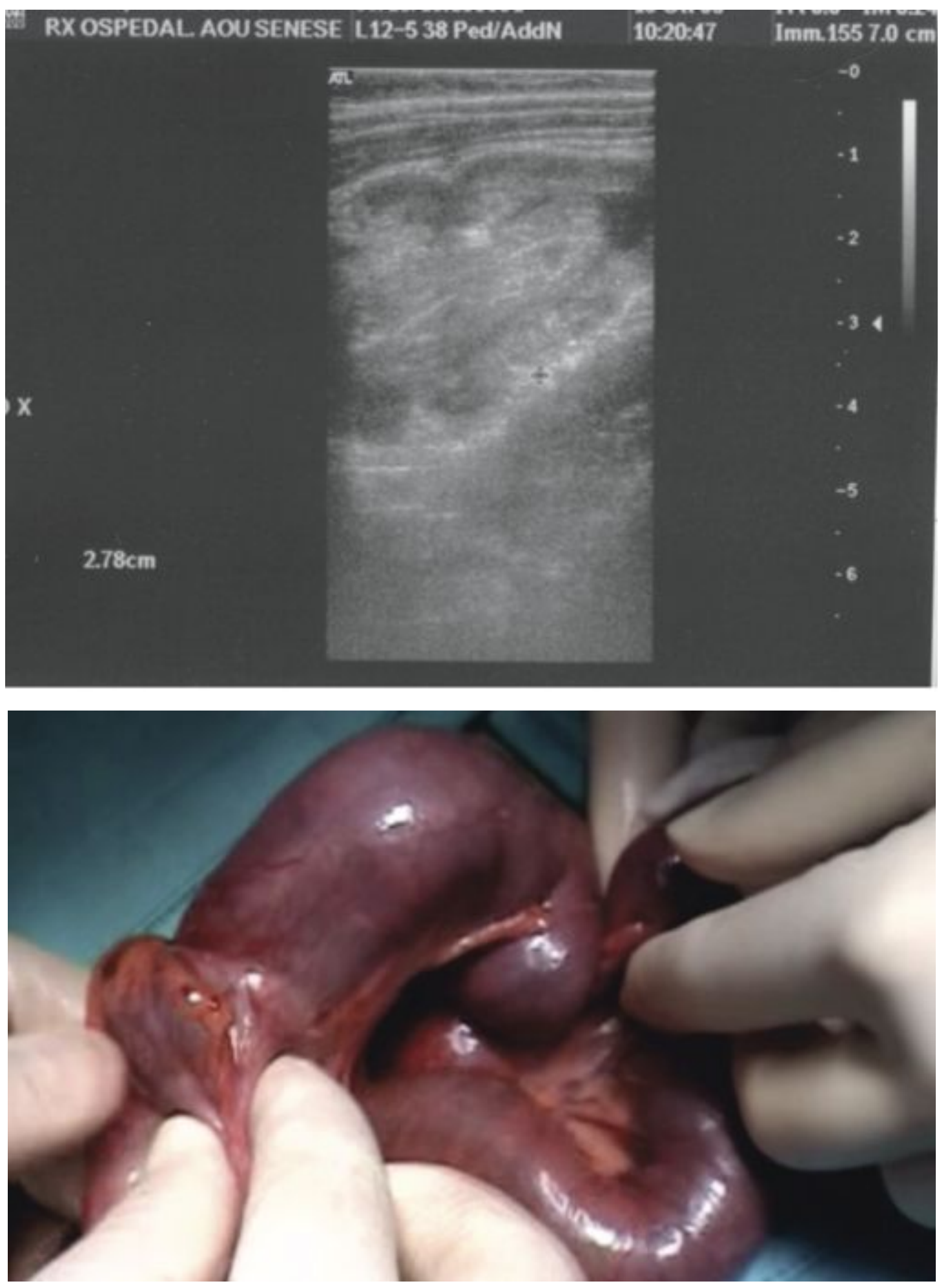

Fig.2:

Intraoperative image; reduction of ileum was achieved by squeezing the bowel distal to the apex of intussusceptum.

Fig.1:

Echography shows an invagination of proximal bowel (intussusceptum) into the lumen of distal bowel (intussuscipiens).

(intussusceptum.

On the 8th postoperative day the patient was dismissed and she was referred to Pediatric Oncology Center for chemotherapy.

\section{Discussion}

Non Hodgkin Lymphoma (NHL) is the third most common cancer $(10 \%)$ and accounts for approximately $60 \%$ all lymphomas in children and adolescents. The four majority pathological subtypes of childhood and adolescents NHL are Burkitt lymphoma (40\%), lymphoblastic lymphoma (30\%), diffuse large B-cell lym- phoma $(20 \%)$ and anaplastic large cell lymphoma $(10 \%)(2)$.

Two clinical variants of Burkitt Lymphoma (BL) have been recognized by World Health Organization classification (WHO): endemic and sporadic, that are indistinguishable by histology, but they have got a different geographical distribution. The etiology of sporadic Burkitt is obscure, it has an abdominal presentation and it's common form in young children of the U.S.A.; the presenting symptoms included: an abdominal mass, intestinal obstruction, intussusceptions and 
acute abdomen. Instead, the etiology of endemic Burkitt is correlated to Ebstein-Barr virus (EBV) and it frequently presents with tumors of the head and neck in population in equatorial Africa. Translocation involving C-MYC gene is constant feature of BL. All cases have a translocation involving C-MYC gene at 8q24 with the immunoglobulin heavy chain gene (IGH) at 14q32, or, less commonly, with k light chain locus (IGK) at 2q11 or lamda light chain locus (IGL) at $22 q 11(4,5)$. The majority of sporadic Burkitt Lymphoma patients present with abdominal disease that required a laparotomy. The presenting intrabdominal symptoms included: an abdominal mass, intestinal obstruction, intussusceptions and acute abdomen. Burkitt Lymphoma is a rapidly progressive malignancy that may present with surgical complications especially in the sporadic form (6). The role of surgery in intrabdominal Burkitt Lymphoma is a controversial subject and there are some different views. Surgeon is required to confirm the diagnosis in the presence of extensive intrabdominal disease and to treat acute abdomen. In the first case the operation should be limited to biopsy only. In the second case, when the tumor is localized and it runs for acute abdomen, the total resection results in a good outcome $(7,8,9)$. Total resection consists in removing neoformation and pertinent lymph-nodes. Treatment is based on the stratification of patients into four risk groups (R1, R2, R3, R4). R1 included patients with completely resected disease and negative histophatological exam of lymph-nodes; R2 with incompleted resected or unresected disease and extrabdominal disease localization or abdominal and LDH levels < 500 IU/l; R3 with unresected abdominal lymphoma and LDH levels between 500 IU/l and 1000 IU/l and patients with bone marrow without CNS (Central Nervous System) involvement; R4 with LDH levels > $1000 \mathrm{IU} / \mathrm{l}$ and with bone marrow and/or CSN involvement $(10,11)$. Our child was graded second risk group (R2) because lymph-nodes sampling was not performed. In addition, surgery may be needed for the management and treatment of complications of the dis-

Fig.3: Intraoperative image;

ileum neoformation (dimensions were $1 \mathrm{~cm} \times 2 \mathrm{~cm}$ ).

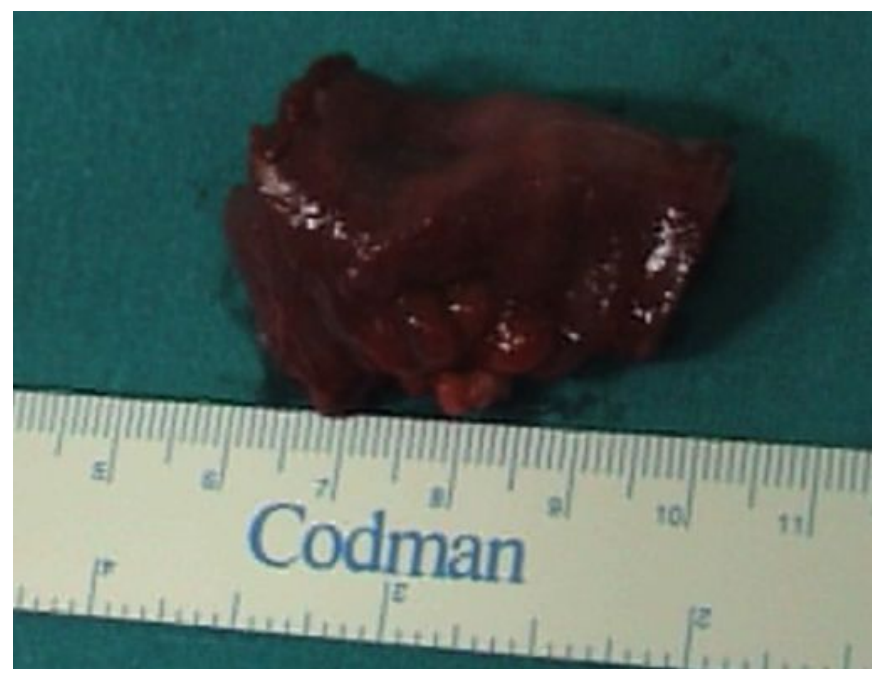

ease. However chemotherapy is the mainstay treatment for all variants of BL, because of its extreme sensitivity. If primary resection has been undertaken this must be followed by chemotherapy (12). This case is paradigmatic situation and it illustrates the importance of considering the possibility of malignancy with ileum neoformation in children. However only histopathological, immunohistochemical and flow citometric immonophenotyping studies can provide a definitive diagnosis.

\section{Conclusions}

In conclusion intussusception in childhood with Burkitt Lymphoma is very common; therefore, the possibility of malignancy in ileum neoformation should be considered in the pediatric patients. So in cases of intussusception, beyond the age of primary invagination and in the presence of a atypical lead point, it's considered the possibility of a malignancy.

\section{REFERENCES}

1.T.W. McLean, R.S. Farber, Z.T. Lewis, M.M. Wofford, M.J. Pettenati, T. Pranikoff, A.R. Chauvenet "Diagnosis of Burkitt Lymphoma in pediatric patients by thoracentesis". Pediatr Blood Cancer 2007; 49: 90-92.

2.A. Gence, C. Sahin, A.C. Celayir, H. Yavuz "Primary burkitt lymphoma presenting as a solitary rectal polyp in a child". Pediatric Surg Int 2008, 24: 1215-17.

3.C. Bellan, S. Lazzi, G. De Falco, E.A. Rogena, L. Leoncini "Burkitt Lymphoma versus diffuse large B-cell lymphoma: a practical approach" Hematol Oncol 2009; 11;27(4):182-185.

4.S.M. Mbulaiteye, R.J. Biggar, K. Bhatia, M.S. Linet, S.S. Devesa "Sporadic childhood Burkitt lymphoma incidence in the United States during 1992-2005" Pediatr Blood Cancer. 2009; 53(3):366-70.

5.M.S. Cairo, E. Raetz, M.S. Lim, V. Davenport, S.L. Perkins "Childhood and adolescent non-Hodgkin lymphoma: new insights in biology and critical challenges for the future" Pediatr Blood Cancer 2005; 45(6):753-69.

6.M.M. Kemeny, I.T. Magrath, M.F. Brennan "The role of surgery in the management of American Burkitt's lymphoma and its treatment" Ann Surg. 1982;196(1):82-6.

7.L. Abbaso \lu, F. Gün, F.T. Salman, A. Celik, A. Unüvar, O. Görgün "The role of surgery in intraabdominal Burkitt's lymphoma in children" Eur J Pediatr Surg. 2003; 13(4):236-9.

8.D.B. Gahukamble, A.S. Khamage "Limitation of surgery in Intraabdominal Burkitt's Lymphoma in Children" J Ped. Surg. 1995; 30 (4): 519-522.

9.B.H. Kaufman, E.O. Burgert, P.M. Banks "Abdominal Burkitt's Lymphoma: role of early aggressive surgery" J Ped. Surg 1987; 22 (7):671-674

10.M. Pillon, M. Piglione, A. Garaventa, V. Conter, M. Giuliano, G. Arcamone, R. Mura, M. Cellini, E.S. D'Amore, S. Varotto, L. Mussolin, A. Rosolen, AIEOP-NHL Committee "Long-term results of AIEOP LNH-92 protocol for the treatment of pediatric lymphoblastic lymphoma: a report of the Italian Association of Pediatric Hematology and Oncology" Pediatr Blood Cancer. 2009; 53(6):953-9.

11.A.H. Eldar, B. Futerman, G. Abrahami, D. Attias, A.B. Barak, Y. Burstein, R. Dvir et all. "Burkitt lymphoma in children: the Israeli experience" J Pediatr Hematol Oncol. 2009; 31(6):428-36.

12. E.S. Wang, D.J. Straus, J. Teruya-Feldstein, J. Qin, C. Portlock, C. Moskowitz, A. Goy, E. Hedrick, A.D. Zelenetz, A. Noy "Intensive chemotherapy with cyclophosphamide, doxorubicin, high-dose methotrexate/ifosfamide, etoposide, and high-dose cytarabine (CODOX-M/IVAC) for human immunodeficiency virus-associated Burkitt lymphoma" Cancer 2003; 98(6):1196205. 